\title{
Observation of Diffusive Flows during Liquid Phase Microwave Sintering
}

\author{
Takashi WATANABE, Motoyasu SATO ${ }^{1)}$, Sadatsugu TAKAYAMA ${ }^{1)}$ and \\ Akihiro MATSUBARA ${ }^{2}$ \\ Toki Municipal Institute of Ceramics, 287-3 Hida, Toki, Gifu 509-5403, Japan \\ 1) National Institute for Fusion Science, 322-6 Oroshi-cho, Toki 509-5292, Japan \\ ${ }^{2)}$ Faculty of Engineering, Chubu University, Kasugai, Aichi 487-8501, Japan
}

(Received 20 January 2008 / Accepted 14 January 2009)

\begin{abstract}
Experiments at the microscopic scale show the shrinking and melting processes of porcelain by microwave and infrared heating. Microscopic in-situ observations reveal that the porcelain is sintered rapidly and volumetrically by microwaves. This experiment clarifies the differences between microwave and conventional heating.

(C) 2009 The Japan Society of Plasma Science and Nuclear Fusion Research
\end{abstract}

Keywords: microwave sintering, in-situ microscopic observation, glass phase, porcelain

DOI: $10.1585 /$ pfr.4.009

\section{Introduction}

Porcelain sintering is the oldest industry in human culture. For thousands of years, civilization has depended upon materials made by transferring the energy of a flame through thermal conduction, convection, and infrared radiation, in order to induce kinetic motion within the elements. Thermal conduction creates a temperature gradient that increases the thermal stress in the material. Superior quality material is obtained with a smaller temperature gradient, but this requires a longer processing time i.e., of the order of days. Porcelain sintering process struggles with this contradiction.

Although how microwave heating works in this process has not been clarified, many experiments [1] have shown that microwaves can sinter porcelain in a few minutes. In this report, sintering process under microwave heating was observed through an in-situ microscope. The results were compared with those of the traditional infrared heating.

Microwaves can transmit electromagnetic energy into dielectric materials and it can couple to the electrons in the crystal structure or in the liquid phase molecules. Experimental results suggest that microwave heating of ceramics can be explained by analogy to plasma heating, as it couples directly to the electrons in the matrix or in the crystals of the materials. Microwave heating does not require energy transfer by thermal conduction, as it is characterized by volumetric heating.

Microwave heating experiments showed improved coupling efficiency and energy balance compared to traditional heating.

author'se-mail: benkeiw@ybb.ne.jp

\section{Heating Devices}

The experiments were conducted in a single mode waveguide cavity (called a microwave furnace in this paper), which consisted of a WRJ-2 $(109.1 \times 56.4 \times$ $149.3 \pm 5 \mathrm{~mm}$ ) waveguide. One end of the cavity was closed by a movable reflector (plunger) and the other end was coupled to the microwave generator through a slotted plate (iris), as shown in Fig. 1. The test piece was placed at the electric field maxima in the cavity (Fig. 2). The volume of the test piece $(11 \times 11 \times 6 \mathrm{tmm})$ was kept small to prevent disturbing the structure of electromagnetic field of the $\mathrm{TE}_{103}$ mode in the cavity. When the test piece was inserted, the cavity length was shortened by a few millimeters to maintain the overall dielectric constant. An insulator made of alumina-silica fiberboard surrounded the porcelain test piece (Fig. 3). Microwave absorption of the insulator is much smaller than that of the porcelain. The temperature of the test piece was measured with an infrared pyrometer.

Infrared heating was compared with microwave heating. The infrared furnace was a reverberator with IR illuminators (called the IR furnace in this paper), as shown in Fig. 4. The test piece $(10 \times 6 \times 5 \mathrm{tmm})$ was about half the volume of the test piece for the microwave experiments. The alumina container (Fig. 5) held the test piece in the furnace, and the temperature of the test piece was measured using a thermocouple.

\section{Microwave Heating for Porcelain}

The porcelain test pieces were composed of kaolin, quartz, and feldspar powder, as shown in Table 1, which contributed their respective characteristics of adhesion, aggregation, and solvency. Calcined, i.e., incompletelydensified, porcelain bodies were prepared as test pieces. The volume and supplied microwave energy were $1.2 \mathrm{~g}$ and 


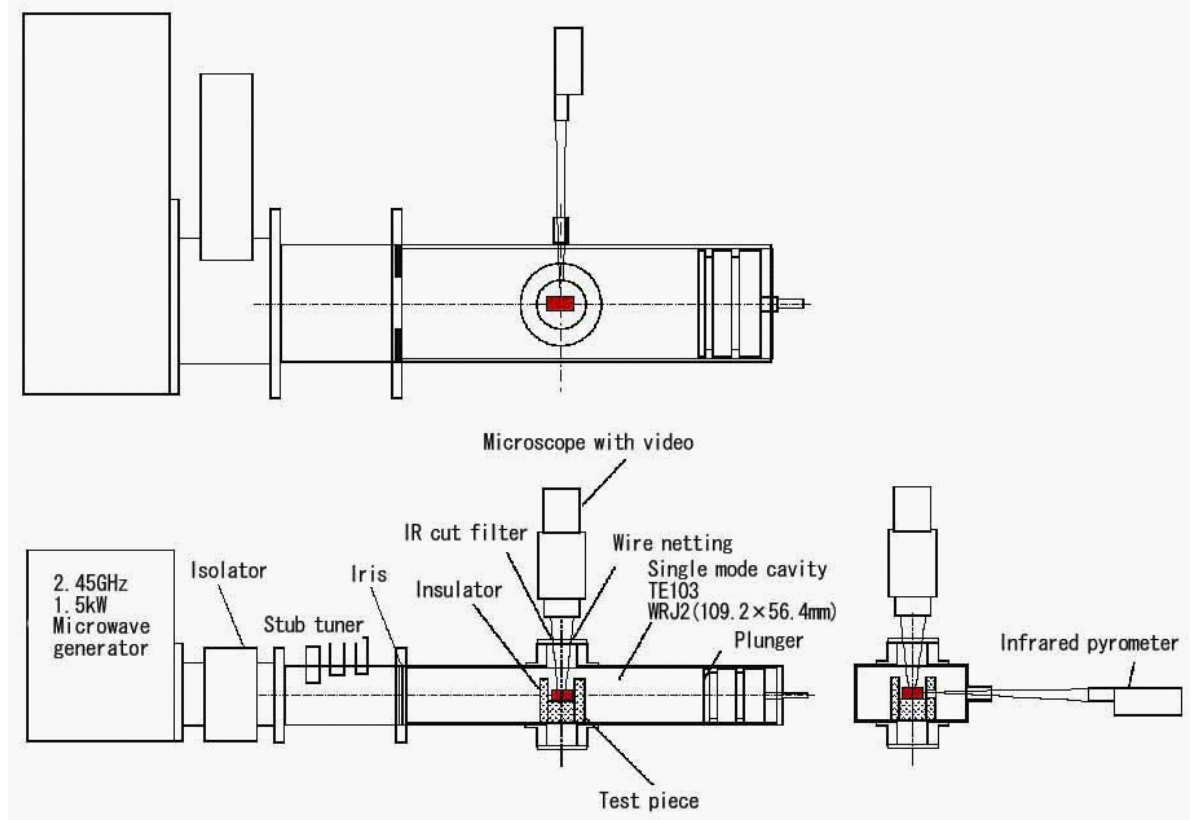

Fig. 1 Device of single mode cavity and microscope with video for in-situ observations.

Table 1 Components of porcelain.

\begin{tabular}{c|c|c|c|c|c|c|c|c}
\hline Components & $\mathrm{SiO}_{2}$ & $\mathrm{Al}_{2} \mathrm{O}_{3}$ & $\mathrm{Na}_{2} \mathrm{O}$ & $\mathrm{Fe}_{2} \mathrm{O}_{3}$ & $\mathrm{TiO}_{2}$ & $\mathrm{CaO}$ & $\mathrm{MgO}$ & $\mathrm{K}_{2} \mathrm{O}$ \\
\hline $\begin{array}{c}\text { Analysis } \\
\text { value }(\%)\end{array}$ & 70.8 & 23.8 & 1.26 & 0.28 & 0.08 & 0.36 & 0.39 & 2.9 \\
\hline
\end{tabular}

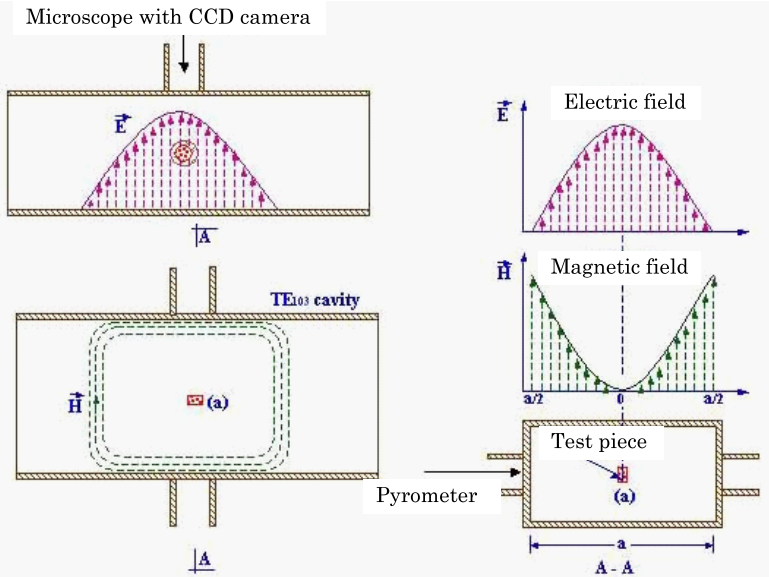

Fig. 2 Distribution of the electromagnetic field in the microwave cavity.

80 watts, respectively.

Changes in the microscopic structures of test pieces in the microwave and IR furnaces, as shown in Figs. 6 and 7 , were observed through a high resolution digital video camera. When the temperature measured with an infrared pyrometer reached 900 degrees Celsius, the liquid phase appeared and the diffusive flow spread over the test piece

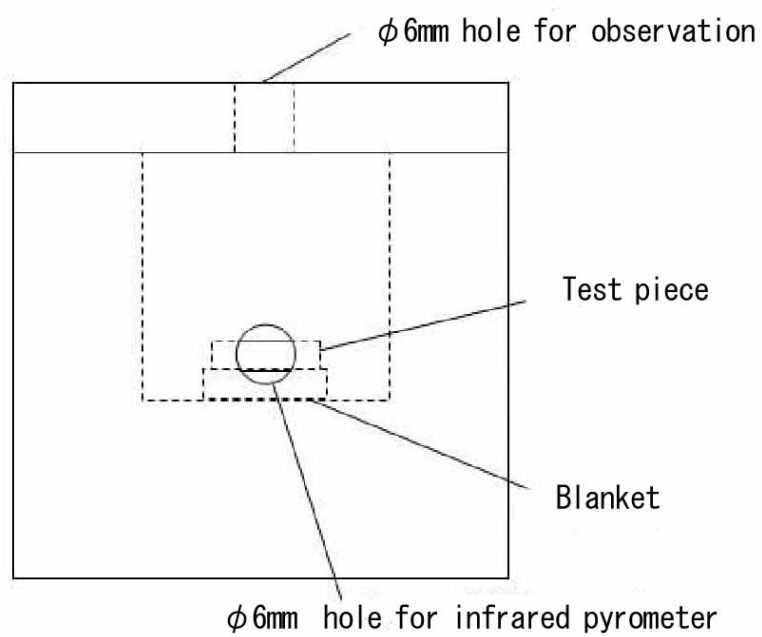

Fig. 3 Test piece and insulator in form of - alumina-silica fiber container $(50 \times 40 \times 50 \mathrm{~h} \mathrm{~mm}$ outside, $20 \times 20 \times 30 \mathrm{~h} \mathrm{~mm}$ inside).

rapidly, as shown in Fig. 6(a). Simultaneously, the distance between pores decreased and shrinking proceeded (Fig. 6). The pores disappeared at 1300 degrees Celsius and sintering was completed in a few seconds. Observa- 
tion after cooling showed uniform structures over the entire cross section of the test pieces in both the microwave and IR furnaces.

The heating curve (Fig. 8) showed variation in the heating rate at 900 degrees Celsius in the microwave furnace. The breaking point corresponds to the endothermal reactions [2] at which the glass phase is generated, which further reacts with the solid components. Since the melting point of the feldspar is the lowest among the porcelain components, and as feldspar most strongly absorbs

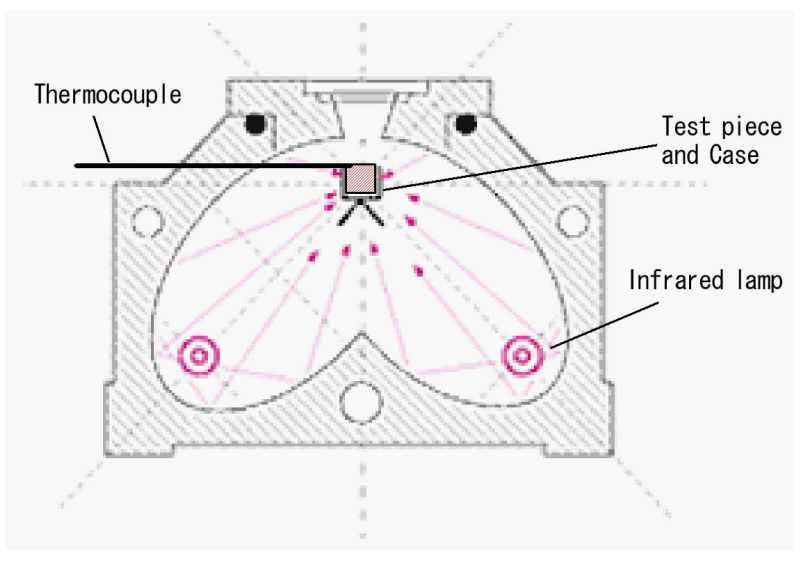

microwave energy, the liquid phase is considered to be that of feldspar, which fills the boundaries of the quartz [3, 4]. The most important observation is that the temperature of 900 degrees Celsius is approximately 220 to 250 degrees below the melting point of feldspar. This can be explained by selective heating of complex materials in a microwave.

In-situ observations showed fine hot spots in the mixed components, as shown in Fig. 9. The temperatures used did not heat the powder uniformly. Infrared pyrometer indicated the average temperature in a $2 \mathrm{~mm}$ viewing circle. Feldspar reached a higher temperature than its surroundings at 900 degree Celsius, which also required a large latent heat on melting. This is why the heating rate hit a breaking point. Feldspar contains sodium atoms in

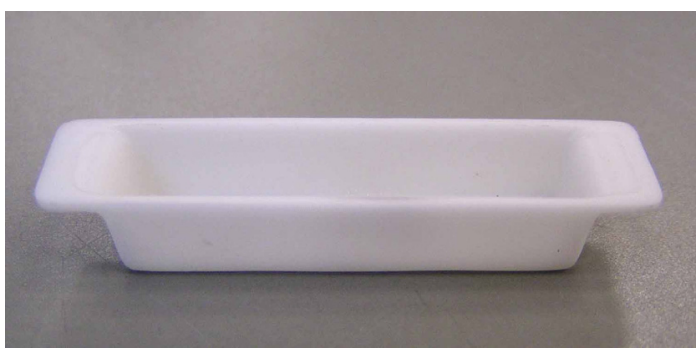

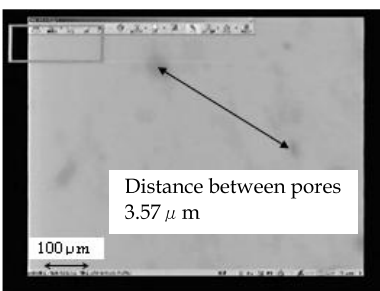

(a)

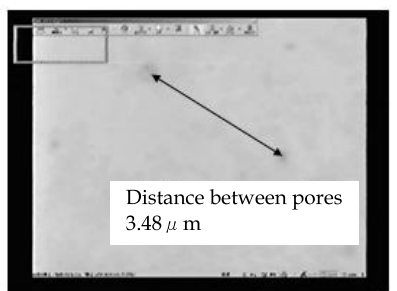

(b)

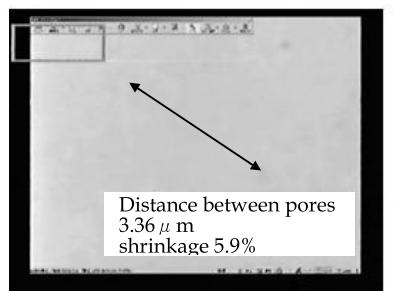

(c)

Fig. 6 In-situ microscopic observations of the microwave sintering of porcelain. The distance between pores is reduced as the temperature increases. The focal length of the objective lens and the magnification are $60 \mathrm{~mm}$ and $200 \mathrm{x}$, respectively. (a) At 890 degrees Celsius the liquid phase appears and spreads over the test piece rapidly within a few seconds; thus, starting the shrinking process. (b) At 1060 degrees Celsius, the distance between two pores decreases. (c) At 1210 degrees Celsius, the distance between two pores decreases even greatly, and finally completing the shrinking process.

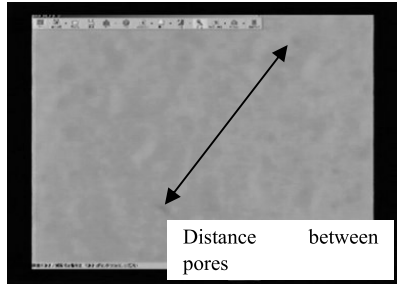

(a)

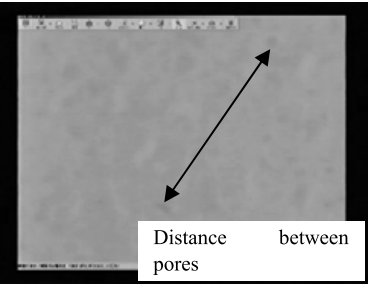

(b)

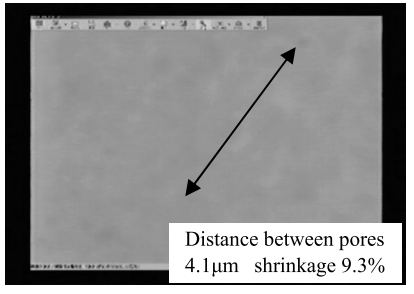

(c)

Fig. 7 In-situ microscopic observations of the IR sintering process of porcelain, which is the same as for microwave sintering. At (a) 950, (b) 1060, and (c) 1200 degrees Celsius. 


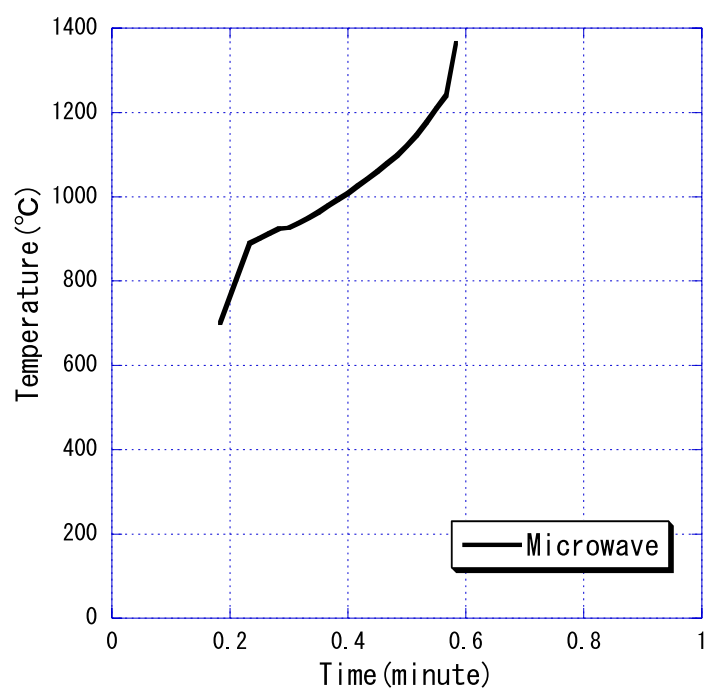

Fig. 8 Heating curves with microwave. It takes 24 seconds to heat from 700 to 1330 degrees Celsius with microwaves. its crystal structure that dissolve into the glass matrix just above the melting point. Because sodium behaves as an ion conductor in glass, the microwave heating rate again increases, making the heating curve concave with respect to time. Thus, sodium influences the excess heating of the glass matrix under microwave irradiation [5]. Further investigation is needed to understand the relationship between sodium and microwave heating.

The microwave heating behavior was compared with that of IR. A test piece weighing $2.8 \mathrm{~g}$ (the test piece $0.5 \mathrm{~g}$, and the alumina container $2.3 \mathrm{~g}$ ) is heated in an IR furnace at 200 watts. With IR heating, the breaking point did not appear at 900 degrees Celsius, and the temperature curve moved smoothly to saturation at 1300 degrees Celsius, drawing a convex curve with respect to time. The breaking point was not as clear as in microwave heating. In-situ observation showed that the liquid phase appeared and diffused within the solid components, reducing pores, and finishing the sintering process, as it did for microwave heating. However, because IR heating requires thermal conduction from the surface to inside the test piece, the

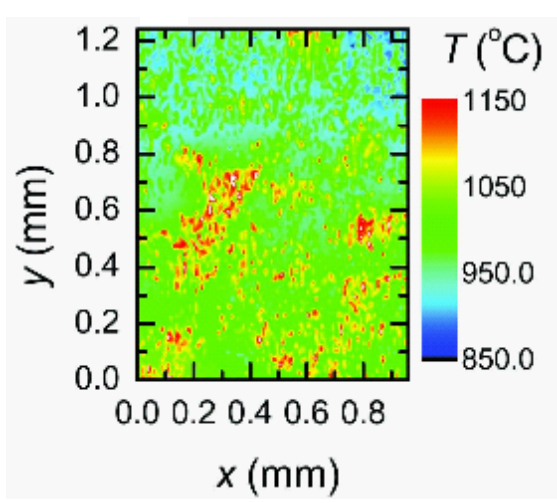

(a)

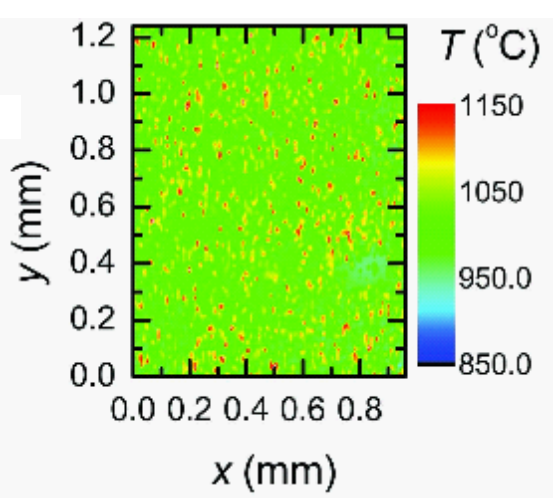

(b)

Fig. 9 Hot spots seen by in-situ microscopic observations of the microwave sintering process. The microwave generates fine hot spots in mixed components of porcelain and clay. Hot spots are porcelain particles that contain sodium glass as a major ingredient. (a) The average porcelain particle size is $250-500 \mu \mathrm{m}$. (b) The average particle size of porcelain is $4 \mu \mathrm{m}$.

Table 2 Heating rates and required energy for the microwave and IR furnace. The required energies are normalized by the weight ratio. The IR furnace requires more energy, and takes longer time than the microwave furnace.

\begin{tabular}{l|c|c|c}
\hline \multicolumn{2}{l|}{} & Microwave heating & IR heating \\
\hline \multicolumn{2}{l}{ Supplied energy } & $80 \mathrm{~W}$ & $200 \mathrm{~W}$ \\
\hline \multirow{2}{*}{ Heating weigt } & Sample & $1.2 \mathrm{~g}$ & $0.5 \mathrm{~g}$ \\
\cline { 2 - 4 } & Container & & $1.8 \mathrm{~g}$ \\
\cline { 2 - 4 } $\begin{array}{c}\text { Process time } \\
700-1330 \text { degree Celcius }\end{array}$ & $24 \mathrm{sec}$ & $2.3 \mathrm{~g}$ \\
\hline $\begin{array}{c}\text { Normalized average heating rate } \\
700-1330 \text { degree Celcius }\end{array}$ & 26.25 degree C/sec & 10.50 degree C/sec \\
\hline Required Energy & $8 \mathrm{k}$ Joules & $28 \mathrm{k}$ Joules \\
\hline
\end{tabular}


processing took five minutes.

Sintering behavior in both the processes was almost identical, involving shrinking, displacement, and disappearance of the pores. The porcelain was sintered by microwave heating similar to that in conventional heating. However, the mechanisms of energy transmittance differ between microwave and IR. Microwave energy in the sample is converted to kinetic energy directly and volumetrically, and the components are heated selectively. On the other hand, the IR energy converts to kinetic energy on the sample surface and transmits into the materials by thermal conduction. Although the melting point of feldspar remains the same whether heated by microwave or IR, the average temperature of the mixed components in the microwave furnace is lower than that in the IR furnace. The liquid phase diffuses into the pores between the solid particles, and thermal energy is transferred from hot liquid to solid particles through liquid-solid contact. Thus, suggesting a possible mechanism for the lower temperature sintering with microwaves.

The energy supplied to the furnaces, the heating weights, and process times are listed in Table 2. Microwave furnace required $8 \mathrm{k}$ Joules, and IR furnace required $28 \mathrm{k}$ Joules, after normalizing by the weight ratio. The heating rates were 26.25 degrees $\mathrm{C} / \mathrm{sec}$ in the microwave furnace and 10.50 degrees $\mathrm{C} / \mathrm{sec}$ in the IR furnace. IR furnace thus requires more energy and longer time than microwave furnace. Observation of diffusive flows during liquid phase sintering at microscopic scales and measurement of the heating rates confirms that porcelain sintering with microwaves is rapid and volumetric.

\section{Conclusion}

These in-situ experiments showed that porcelain could be sintered by microwaves volumetrically and rapidly. These observations are the first to show the shrinking and melting processes of porcelain during microwave and IR heating on a microscopic scale. The experiments clearly revealed the differences in energy transfer mechanisms between the microwave and IR furnace. The electromagnetic energy flows from the microwave generator into the volume of compacted porcelain powders, undergoing these processes sequentially: producing feldspar particle melt, feldspar formation of liquid sodium glass, diffusion of the liquid phase into the pores, and finally heating of solid components (quartz and kaolin) by thermal conduction. IR light, on the other hand, is absorbed on the surface of the compacted powders and transmitted into the compacted powders by thermal conduction.

Rapid and volumetric sintering by microwave can be energy saving, low on $\mathrm{CO}_{2}$ emission, distortion decrementing, finally leading to low cost sintering of ceramics. The environmental load will be reduced by sintering with microwaves.

[1] M. Sato et al., Ceramic Transaction 111, 277 (2001).

[2] K. Hamano, Fine Ceramics Hand Book (Asakurasyobou, 1984) p.303 [in Japanese].

[3] H. Takashima, Practical Chemistry of Ceramics (Utida Rokakuho Publishing Co., Ltd, 1996) p.41 [in Japanese].

[4] Ceramic Society of Japan, Ceramics Chemistry (Ceramic Society of Japan, 1974) p.96 [in Japanese].

[5] E.B. Shand, Glass Engineering Handbook (McGraw-Hill Book Company, 1958) p.14. 